agreement to promotion terms and usage of personal data) and an action on Facebook.

(The Facebook promotions announcement can be found at: https://www .facebook.com/facebookforbusiness/news/page-promotions-terms.) (The revised Facebook Pages terms can be found here: https://www .facebook.com/page_guidelines.php.)

(New Facebook Promotion Guidelines, including an example that would not previously have been permitted, can be found here: https:// fbcdn-dragon-a.akamaihd.net/hphotos-ak-ash3/ 851577_158705844322839_2031667568_n.pdf.)

Nick Johnson, Partner, advertising and sponsorship law, Osborne Clarke

\title{
Did use of YouTube targeting function ensure age gate kept shut?
}

\section{Thomas Spanyol}

Journal of Direct, Data and Digital Marketing Practice (2013) 15, 149-151. doi:10.1057/dddmp.2013.67

What happened

How the game was advertised
Who: Advertising Standards Authority, Zenimax Europe Ltd Where: The United Kingdom

When: 18 September 2013

Law stated as at: 3rd October 2013

The Advertising Standards Authority ('ASA') recently ruled on a complaint regarding an online advert for an upcoming computer game. The game in question is called 'The Evil Within' and is in the 'survival horror' genre. This game's target demographic is males aged 18-35 years (see below) and the aim is for the player to help the main character survive in a hostile, gruesome and often post-apocalyptic environment. The game was rated by PEGI, the Europe-wide board that assigns age ratings to interactive entertainment products, with an 18 certificate.

The advert in question took the form of a video advert on YouTube, which was shown to certain targeted users before viewing YouTube videos they had requested. The advert could be skipped after $5 \mathrm{sec}$. This type of advertising is known as a 'skippable pre-roll'. As might be expected from a survival horror game, the advert created a sense of apprehension and was gory. The ASA reported that features included images of 'a person covered in shards of glass', 'a flayed corpse wrapped in barbed wire', 'a bubbling 


\section{When survival horror meets Sodor}

\section{How could this happen?}

\section{The advertiser's response}

\section{The ASA's view: not responsibly targeted and too gory}

pool of blood, out of which a bloodied creature rose' and 'a man's head, exploding into bloody tentacles'.

A complaint was made to the ASA by an internet user who had signed into the YouTube site and searched for YouTube videos of a children's play set featuring well-known blue locomotive 'Thomas the Tank Engine'. The above advertisement for 'The Evil Within' was played to the user as a pre-roll immediately before the video about the play set. This must have been quite a contrast. The complainant also claimed to have been served the same advert when he viewed the YouTube site when he was not signed in.

The bases of the subsequent complaint to the ASA were as follows:

1. the advert had been irresponsibly targeted as it appeared before a video that would appeal to children; and

2. the advert was distressing and offensive as it was excessively gory.

The publisher of the game (Bethesda Softworks, a group company of Zenimax) ('Bethesda') had instructed its external advertising agency to place the ad. Bethesda stated that it had asked the agency to target only logged-in, male YouTube users, aged 18-35. Skippable pre-roll ads on YouTube are placed and targeted using Google's proprietary AdWords platform. However, Bethesda's understanding of how YouTube ads work was that the AdWords platform targeted based on a blend of sign-in information and 'inferred information', and therefore there could be no guarantee that an ad would never be served to someone who was not signed in.

Inferred information consists of a variety of factors. These include the user's browsing history, IP address, search history and cookies on the user's machine. In this case, Bethesda explained that the inferred information may have profiled the complainant as someone interested in horror movies, computer games and potentially also Bethesda's computer games in particular. It was likely that AdWords had therefore identified the complainant as someone who would be interested in that particular ad and served it accordingly, even when the complainant was not logged in.

Bethesda felt that it had done enough to limit the target audience and to avoid causing serious or widespread offence, fear or distress without justifiable reason; the ad had clearly been labelled with a PEGI 18 rating at the start of the video, and it believed that the user could immediately skip the content if they were under 18 years of age. The screenshot that had been provided to the ASA by the complainant also came from a section of the advert that was well after the 5-sec point at which the pre-roll was skippable.

The ASA found that the advert had not been responsibly targeted. Its reasoning was that even though Bethesda had specified to its agency that the ad should only be served to logged-in users fitting a certain profile, there was still a possibility that the same ad could be served to non-loggedin users due to their inferred information. This being the case, there remained a possibility that users under the age of 18 years whose cookie and browsing history indicated an interest in horror and computer games 
could be served an 18-rated advert. As such, the advert breached rule 1.3 of edition 12 of the CAP Code: social responsibility.

The ASA also found that, notwithstanding the genre of the product, even if only over-18s had seen the advert, it was simply too gory and was likely to cause distress and offence to some who saw it. Rules 4.1 and 4.2 of the CAP Code were found to have been breached. Because of the above, the ASA ruled that the ad should not appear again in its current form.

Why this matters

Both counts of the ASA's decision raise some interesting issues. On the first point, advertisers and agencies contemplating age-restricted content in pre-roll advertising need to have a clear appreciation of any targeting technology being used and consider in particular the potential implications of possible 'inferred information' targeting.

Advertisers should also remember that the terms and conditions of AdWords leave them responsible for ASA compliance (YouTube made this point to the ASA in the adjudication). If advertisers rely on the accuracy of the platform's demographic targeting to comply with their obligations, they therefore do so at their own risk. Such risk could of course be mitigated through age-gating, but this may not be practical for pre-roll advertising.

On the ASA's second point, creatives should take note that, regardless of how much a segment of the male population aged 18-35 years may enjoy computer games involving broken glass, blood, barbed wire and/or tentacles, it appears that some types of ad content will not be approved by the ASA, even if the game containing such footage has been granted an age rating by the relevant ratings body and age-gating technology actually works.

\section{The safety of Safe Harbor}

\section{Emily Jones}

Journal of Direct, Data and Digital Marketing Practice (2013) 15, 151-154. doi:10.1057/dddmp.2013.68

Who: European Commission

Where: Brussels, Belgium

When: 19 July 2013

Law stated as at: 4 September 2013

What happened

The European Commission has announced an assessment of the EU-US Safe Harbor agreement and will present its results by the end of 2013. Vice President Viviane Reding explained at a European Justice Council meeting held on 19 July 2013 that 'the Safe Harbor agreement may not be so safe after all', adding that 'it could be a loophole for data transfers because it 